\title{
Developing Primary Care: The Contribution of Primary Care Research Networks
}

\section{Développement des soins de santé primaires : contribution des réseaux de recherche en soins primaires}

\author{
(3) \\ STEPHEN PECKHAM \\ Professor of Health Policy \\ Director, Centre for Health Services Studies \\ University of Kent \\ Canterbury, Kent \\ BRIAN HUTCHISON \\ Professor Emeritus, Clinical Epidemiology and Biostatistics \\ McMaster University \\ Hamilton, ON
}

\begin{abstract}
The performance of Canada's primary care sector remains lacklustre relative to other wealthy industrialized countries, and it has been suggested that a lack of investment in research and evaluation may be a cause. One approach to improving and sustaining primary care research is through research networks. Over the past few years, significant investments have begun to be made in developing primary care networks in Canada. While Canadian experience in this area is relatively new, in the United Kingdom primary care research networks were first established in the 1980s. Initially developed at a local level, these have more recently been incorporated into large-scale national networks. This paper reviews the UK experience and highlights potential lessons for the development of networks in Canada.
\end{abstract}




\section{Résumé}

Le rendement du secteur canadien des soins de santé primaires demeure relativement médiocre par rapport à celui des autres pays riches industrialisés. Un manque d'investissement dans les activités de recherche et d'évaluation pourrait en être une des causes. Les réseaux de recherche constituent une façon d'améliorer et d'assurer la durabilité de la recherche dans le domaine des soins primaires. Au cours des dernières années, d'importants investissements ont été effectués pour favoriser le développement de réseaux de recherche en soins primaires au Canada. Alors que cette pratique est relativement nouvelle au Canada, de tels réseaux de recherche ont été créés au Royaume-Uni à partir des années 1980. D’abord développés au niveau local, ces réseaux ont été récemment intégrés en réseaux nationaux à grande échelle. Cet article examine l'expérience du Royaume-Uni et en fait ressortir des leçons potentielles pour le développement de réseaux au Canada.

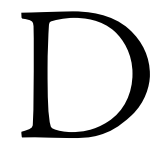
ESPITE SIGNIFICANT INNOVATION DURING THE PAST DECADE (HutCHISON ET al. 2011), the performance of Canada's primary care sector remains lacklustre relative to other wealthy industrialized countries (Schoen et al. 2009, 2010, 2012). The late Barbara Starfield (2008: 59) suggested that "[o]ne reason for this lack of movement may be the poor investment in primary care research and evaluation. In this regard, Canada is probably at least 10 years behind."

In September 2000, the First Ministers of Canada (the prime minister and the provincial and territorial premiers) agreed that "improvements to primary health care are crucial to the renewal of health services." In response, the federal government established the \$800-million Primary Health Care Transition Fund (PHCTF), which continued to 2006. Funding was distributed to the provinces and territories on a per capita basis to support the introduction of new approaches to primary healthcare delivery. The PHCTF also supported a variety of panCanadian initiatives to identify barriers to progress and develop strategies to address them. As Grzybowski and Wallace (2006) observed, "The vast majority of this funding [was] dedicated to clinical program implementation, often without the necessary research in place to underpin the programs." Some provinces, notably Ontario and Quebec, committed significant funding to research and evaluation of primary care innovations, giving rise to research collaborations that attracted health services researchers whose previous work was in other areas and to the development of substantial research infrastructure focused on primary care. However, following the end of the PHCTF, there were no dedicated funding streams to support the continuance of the research teams and infrastructure that had been established (Russell et al. 2007).

Development of the Canadian Primary Care Sentinel Surveillance Network (CPCSSN) began in 2008 under the sponsorship of the College of Family Physicians of Canada with funding from the Public Health Agency of Canada (Birtwhistle 2011). The network brings together 10 practice-based research networks associated with departments of family medicine 
to pool de-identified patient health information from electronic medical records, forming a database on eight chronic diseases and neurologic conditions. The data are used to produce surveillance reports on chronic disease and to support primary care research. Participating physicians are provided with feedback about their patients with chronic conditions and comparisons with regional and national data. Currently, about 300 physicians and 300,000 patients are represented in the database. CPCSSN serves a coordinating function among practice-based research networks, most established in the last decade, that previously worked in isolation.

In January 2011, the Canadian Institutes of Health Research (CIHR) approved Community-Based Primary Healthcare (CBPHC) as one of eight Roadmap Signature Initiatives. The Transformative Community-Based Primary Healthcare Initiative, formally launched in February 2012, will support Innovation Team grants, Health Professional Scientist awards and a Patient-Oriented Community-Based Primary Healthcare Network (CIHR 2012).

Up to $\$ 31,915,000$ over five years is available for the team grant competition. Of the 85 responses to the call for letters of intent, 78 team grant applications were deemed eligible for review. Successful applicants at the letter of intent stage (approximately 35) will be invited to submit a full-scale application, with an anticipated decision and funding start-date of April 2013. The teams are expected to undertake "programmatic, interdisciplinary, cross-jurisdictional research; build capacity for research excellence; and foster integrated knowledge translation approaches that contribute to new and improved models of CBPHC delivery in two key research priorities: (a) chronic disease prevention and management in CBPHC and (b) access to appropriate CBPHC for vulnerable populations (CIHR 2011a). Funding of $\$ 500,000$ per year for up to five years will be provided to approximately13 teams.

The CBPHC Health Professional Scientist award is a new award designed to support "health professionals working in CBPHC settings, providing protected time for health system leadership (including clinical practice) and research. These scientists will provide grass-roots leadership for transformative change and act as role models and mentors for a cadre of new health professional scientists in CBPHC" (CIHR 2012). The call for applications for these awards has yet to be issued.

The Patient-Oriented CBPHC Network is one of several networks that will be funded as part of Canada's Strategy for Patient-Oriented Research (SPOR). The network will have three core functions: (a) research priority-setting, coordination and dissemination; (b) supporting the investigation of new clinical, health services and population health interventions relevant to CBPHC; and (c) supporting the collaborative development of new research and training programs for $\mathrm{CBPHC}$ researchers. As part of its coordinating function, the network will be required to engage with and support the CBPHC Innovation Teams and Health Professional Scientists as well as senior decision-makers. The Patient-Oriented CBPHC Network (and other SPOR networks) will be expected to obtain funding from multiple sources and to engage national associations, health charities, clinicians, industry, patients and the public. Network funding could range from $\$ 500,000$ to $\$ 10$ million per year for 10 years. A call for applications for the Patient-Oriented CBPHC network is expected some time within the next year. 
The precise form of the Patient-Oriented CBPHC Network, including the networks relationship with CPCSSN and the CBPHC Innovation Teams, will be shaped over the next one to two years. This paper discusses concepts of knowledge production and use, describes and reflects on efforts in the United Kingdom (UK) to build capacity in and support primary care research and draws lessons from the UK experience that might have application in the Canadian context.

\section{Supporting Primary Care Research}

The increasing importance being placed on the role of primary care within health systems raises questions about how an appropriate evidence base for practice can be supported, developed and applied. A simple view of knowledge production and use would see this as a linear process, whereby scientists find out new things about the world that are published in academic journals. Then people who want that knowledge search for it and put it into use. In this classic knowledge-driven model, research generates knowledge, which impels action; thus, where knowledge is generated and by whom is less relevant than ensuring the production of high-quality research findings (Hanney et al. 2003). As many commentators have pointed out, however, this is an oversimplified view of a complex process (for example, Weiss 1979; Thomas 1985.

An interactive, social model of knowledge is more useful. Gibbons and colleagues (1994) make the case for two "modes" of knowledge production. In mode one, the main objective is to produce new knowledge that builds on a solid stock of prior discipline-based knowledge. The most valuable form of diffusion for mode one knowledge is publication in academic journals, which are reviewed and thus quality-controlled by academic peers (this resembles the classical knowledge-driven model). In mode two, the main objective is to develop problem-solving capabilities in society at large. Research problems are developed from interaction between researchers and other social actors. As Sweeney and colleagues (1998) argue, research not only needs to be statistically and clinically relevant but there should also be recognition of personal significance and the importance of applying research evidence to the individual within the social context. The value of that knowledge is mainly found in its use by non-academics. Similarly, Dobrow and colleagues (2004) distinguish between normative-philosophical (like mode one) knowledge, which is unconstrained by context and relates to evidence seen as of a higher level of quality than practical-operational evidence (mode two), which is context-based and defines evidence more by its relevance.

Mode two appears more suitable for primary care, where service delivery needs to be supported by research that is both appropriate and context-relevant and is, therefore, best conducted within primary care. De Maeseneer and colleagues $(2003: 1316)$ have argued that "[c]ontextual evidence is necessary to assist doctors to address the challenge of how to treat a particular patient in a given situation." Hospital-based clinical research is not always relevant to the primary care context, and the findings of clinical trials based in secondary care cannot easily be translated into primary care practice. In addition, primary care practice involves an interest in the appropriateness of care and low-technology interventions as well as new drugs (Carter et al. 2000; Green and Hickner 2006; Thomas et al. 2001). 
In a study of health service utilization in the United States, it was found that in an average month in a population of 1,000 adults and children about $80 \%$ report symptoms, and some $21 \%$ visit a doctor's office (in the United States this is split between primary [113] and specialist [104] doctors). Only 8 patients were admitted to hospital, and of these only one to an academic centre (Green and Dovey 2001). A similar analysis in Ontario by the Institute for Clinical Evaluative Sciences estimated that in any 24-hour period 137,000 people visited a primary care physician, 54,000 saw a specialist and 3,000 were admitted to hospital (Jaakkimainen et al. 2006: 5). Given that the focus in hospital is also on specific diseases and diagnoses, it is clear that hospitals as a context for medical research differ substantially from primary care. Yet a study of NICE guidelines in the United Kingdom found that such evidence is often used to support guideline recommendations in primary care (Scullard et al. 2011).

Research in primary care also needs to move beyond clinical research to include delivery systems, and here there is an overriding imperative for such research to be conducted in a primary care context to ensure that research is relevant and hence more likely to be transferred to practice. One important driver for primary care physician involvement in research is the need to improve quality of care (Mold and Peterson 2005). In the United States, the Agency for Healthcare Research and Quality has invested funding in supporting primary care practicebased research networks (PBRNs) and funded studies on ambulatory care patient safety and the impact of working conditions on the quality of care delivered in primary care (Burstin and Lanier 2001). Mold and Peterson (2011) highlight the role of such PBRNs as learning communities and engines for the improvement of primary care delivery systems. However, there are elements of mode one, which remain relevant, and striking a balance between the two modes is a challenge for research funders and for developing structures and processes for research that combine mode one and mode two approaches.

There are a number of different approaches to supporting primary care research, including:

- Academic primary care research units

- University training in research methods

- Developing research on primary care

+ Developing research in primary care

Such approaches do not, however, necessarily support stronger and more relevant primary care research. Without collaboration with practices, academic centres may remain remote from practitioners and may focus on clinical research driven by academic output criteria such as publications and research income. Training in research methods is clearly a good approach to capacity building, but such training needs to be rooted in relevant methodological approaches for primary care research that include non-trial methodologies, complex interdisciplinary research, organizational research and qualitative methods. Similarly, research on primary care but not involving primary care reduces practices to research sites and may lead to alienation from research. Finally, research based in primary care may simply be using practices as loca- 
tions for research which, while meeting the contextual requirements, may not increase capacity in primary care research.

In order to address some of these weaknesses, networks of researchers in primary care began to develop in the late 1970s and 1980s in a number of different countries. Networks are an ideal organizational form to bring together mode one and mode two approaches to generating knowledge. Primary Care Research Networks (PCRNs) have been recognized as an important structural approach for developing primary care research. The general aim is to stimulate the development of appropriate research that reflects the context of healthcare practice in a primary care setting. Many countries have invested in PCRNS, including the United States, Australia and New Zealand. However, perhaps the most extensive development of PCRNs has been in the United Kingdom and, at a time when changes in national health research funding and structures have led to substantial changes to the structure of primary care research, it seems appropriate to examine the UK experience of PCRNs and identify lessons that could inform the development of primary care research in Canada.

PCRNs provide an ideal approach to achieving an interactive model of knowledge production and utilization. Priority-setting of research topics needs to be designed to identify those areas in which research investments are most likely to improve services rather than simply reflect the interests of the research community (Stryer et al. 2000). This implies significant representation in the process from those who deliver, manage and receive services (Lomas et al. 2003). These ways of identifying research topics help to ensure that there is "pull" for the research, as well as "push" from funders and researchers after the results are produced (Nutley and Davies 2000). But "pull" may not be enough. A further stage in improving the interactive model of knowledge production and utilization is what the Canadian Health Services Research Foundation (CHSRF) calls "linkage and exchange" (CHSRF 1999). Good-quality, useable research emerges from an ongoing relationship among researchers, research funders and potential research users. At a policy level, this has been seen as the need to develop policy networks and policy communities. In primary care, building networks of primary care practitioners and embedding research within this community through the development of networks provides an ideal approach to bringing together mode one and mode two knowledge production and ensuring a more interactive approach to knowledge production and utilization.

Possible research roles:

- Using research to improve the quality of service delivery for patients

+ Participating in sites for research

+ Collaborating in research

+ Leading research

\section{Primary Care Research Networks in the United Kingdom}

The first research networks of general practices in the United Kingdom developed in the late 1960s and early 1970s with the collection of morbidity data and the establishment of the 
Medical Research Council (MRC) hypertension project involving over 1,000 practices. In addition, in 1969 a general practice research club was established to foster research collaboration. In the mid-1980s, a research network was established by a department of academic practice in central England, followed in 1993 by emerging networks in southern England based in the Wessex region and the Northern Primary Care Network.

In the United Kingdom, primary care research networks developed from predominantly local movements to support the development of primary care research by providing expert support, resources and training for local primary care staff. While initially focused on physicians and medical research, most networks encouraged the involvement of nurses, managers and allied health practitioners working in primary care. These first networks were supported by committed practitioners, local funding sources and support from other local research organizations such as academic departments of general practice, research support units and primary care teaching networks.

The growth of networks was stimulated in the United Kingdom by the 1996 White Paper Primary Care: Delivering the Future and by a change in research funding when Culyer money (funds allocated to the NHS for research) was extended to primary care. A study of 23 PCRNs in 1997 found that the organizational structure, staffing and funding of networks varied considerably (Evans et al. 1997). At that time there were three national networks, with the others being local or regionally based. Most networks had funding of less than $£ 100,000$ per annum (ranging from $£ 0$ to $£ 65,000$ ), but two local networks covering 600 and 310 practices received $£ 275,000$ and $£ 165,000$, respectively. The study of PCRNs found that they were funded mainly by regional health authorities and were mainly hosted within an academic unit of primary care, although five were hosted in a general practice. The majority (16) had a steering group and a formal membership, with three charging a membership fee $(£ 5-£ 10$ per person, $£ 10-£ 30$ per practice). Most included some secretarial support, a part-time director and some expert research staffing - either employed in the network or contracted to work with network members. The three national networks included the Royal College of General Practitioners (RCGP) research club with 85 members, the RCGP research network (which was not a membership network) and the MRC General Practice Research Framework (MRC GPRF), with 900 practices that provided sites for large-scale clinical trials. In 1998, in response to policy and funding changes, a national federation of PCRNs was established which had 30 members by 2001 (Thomas et al. 2001).

Four distinct aims were identified within the PCRNs. The majority of PCRNs identified promoting high-quality research by primary care practitioners and promoting research awareness among primary care practitioners as key aims. Seven PCRNs also aimed to promote highquality collaborative projects among primary care practitioners, and two (national MRC GPRF and one regional) sought to recruit practitioners to collect data for high-quality, academically led research. Most PCRNs were developed from informal networks existing locally or by building on established academic research units or local research development and support units (RDSUs), which existed to support local health researchers across the United Kingdom. 
In some cases, regional health authorities invested in development, providing resources to existing academic departments of general practice/primary care together with local RDSUs to extend their activities to include practices and develop networks. In one London region, a highly structured PCRN was established (STaRNet), primarily to support large-scale clinical trials.

The PCRNs have undertaken a wide range of activities including the collection of morbidity data, clinical research, practice-based research, large multi-centre trials, research training, supporting research development, dissemination and knowledge exchange (Evans et al. 1997; Rait et al. 2002; Thomas et al. 2001). There is also good evidence to demonstrate that UK PCRNs focused on developing a research culture and a broad range of research including clinical research, social research, organizational research and research into complex interventions (Hay et al. 1999; Lattimer et al. 1998; O’Neill and Kelly 1996; Bradley et al. 1999; Jolly et al. 1999; Rait et al. 2002). A key advantage of the regional PCRNs was that they seem to be able to sustain "large scale collaborative projects and small scale personally developed projects at the same time" (Thomas and While 2001). In a study of three London-based PCRNs, Thomas and colleagues (2006) found that the networks supported 133 projects involving 399 individuals, of whom 277 (69\%) did not have an academic position. Of the non-academics, 118 were general practitioners and 148 other primary care professionals or managers. In reviewing the management, organization and activity of these networks, Thomas and colleagues (2006) concluded that "generic primary care networks could help integrate academic and service initiatives for research purposes and, equally importantly, development purposes." The study of these four networks also compared different organizational types and highlighted the benefit of combined top-down and bottom-up or whole-system approaches to organizational leadership. The benefits of ensuring that informal networking and building networks that engage front-line practitioners has also been shown in other studies of networks and PCRNs (Goodwin et al. 2004). In fact, PCRNs may be most productive when developed as informal trust-based networks (Griffiths et al. 2000; Thomas et al. 2006).

From the late 1990s, the national government started to provide support funding for networks, and regional health authorities sought to support and enhance local networks. The aim was for greater coordination of activities, greater investment in research support services and skills development and provision of a forum for developing research based on practice. The support provided and the approach were essentially to foster local relationships and build networks from the ground upwards so that staff working in primary care drove the development. The experiences of the networks described earlier suggests that this strategy was effective. However, there was an increasing national interest in the role of these networks and the need to develop a stronger base for supporting national clinical priorities. The Department of Health (2006a) was increasingly becoming concerned about the coordination and impact of the different funding strands for health research from the government, directly from the Department of Health and through the research councils. In 2005 the government instigated a review of health funding by Cooksey who reported in 2006 (Department of Health 2006b). The report identified the lack of coordination between programs, key implementation gaps 
between bench and applied research and between applied research and research use. The UK Treasury was also concerned that unless mechanisms were put in place to support pharmaceutical research, the United Kingdom might lose major pharmaceutical manufacturers. As a result, the government streamlined health research funding and disbanded small research networks to establish national research networks, schools of research and a nationwide clinical research network to support research in the NHS. Funding and support for the existing primary care networks was stopped. A new system of national clinical research networks, including primary care, was established with eight "local" primary care research networks under the auspices of the National Institute for Health Research (NIHR) with the aim of supporting larger-scale clinical trials (Department of Health 2006b). The network brings together a wide range of primary care health professionals and aims to promote high-quality research in areas for which primary care has particular responsibility (such as disease prevention, health promotion, screening and early diagnosis, management of long-term conditions). The networks support research that meets the priorities of the NHS and the Department of Health, with practices acting mainly as research hosts (Howe et al. 2009). There is a focus on clinical research and, in particular, national clinical drug trials. Much of the emphasis on support and development of research and research skills has been stopped, with a focus on supporting larger-scale trials involving general practice. The networks are also much larger, covering eight regions, and are more removed from contact with practices with a far more bureaucratic structure modelled on a national template. The new networks are more clinically focused and do not have the broader developmental role of the previous PCRNs.

In the United Kingdom there has, therefore, been a shift in emphasis from building capacity and research activity (including research training, building a research culture and supporting primary care research leaders locally) to supporting engagement and participation in studies. Whether the new arrangements will provide the structure to facilitate and support primary care research, improve research capacity building and enhance local partnerships between primary care and academic centres has yet to be examined. The shift to an emphasis on clinical research has meant that the networks do not encompass the wider primary care workforce as the previous networks did. Nor is there the emphasis on building relationships among practices, practitioners and research communities (such as academic centres). This may be at the expense of nursing, allied health and primary care management professionals who are keen to develop research and those practitioners who are more interested in research application or small-scale, local studies.

\section{Assessing the Impact of PCRNs in the United Kingdom}

Did PCRNs live up to expectations, and do they provide an effective approach to developing and supporting primary care research? There have been a number of approaches to assessing the development and impact of UK primary care networks (Evans et al. 1997; Thomas et al. 2001; Fenton et al. 2007). One problem about assessing impact is the lack of agreed frameworks for assessment (Bleeker et al. 2010). However, the UK experience highlights some 
important lessons for the development of primary care research networks where similar patterns of primary care exist.

The study by Evans and colleagues (1997) also explored what kinds of outcome indicators should be used to assess the success of PCRNs. Structural indicators included having a database of members, a multidisciplinary membership, appropriate skill base of network staff and the number of active members/practices. Process indicators included degree of research awareness, numbers of courses, numbers of people attending research courses, number of requests of support made to the PCRN, number of collaborative projects, number of grant applications and the number of research projects. Finally, outcome indicators included changes in local clinical practice to improve care for patients, numbers of peer-reviewed publications and conference presentations, completed research projects and success rate in grant applications. Examples of potential impacts that can be measured are shown in Table 1.

TABLE 1. Comparing local and national primary care research networks

\begin{tabular}{|l|l|}
\hline Local primary care networks & National primary care networks \\
\hline Locally driven with greater practitioner support & Conform to national clinical/commercial agendas \\
\hline Engage wider practitioner and non-clinical primary care workers & Tend to be clinician, mainly physician-focused \\
\hline Develop and support local initiatives & Provide support for national concerns \\
\hline Provide a basis for building wider local networks & Tend to be insular from other networks \\
\hline Strong research "buy-in" by local primary care organizations & Primary care organizations function as locations for research \\
\hline
\end{tabular}

Two broad areas of activity can be discerned. The first is contributing to the expansion and embedding of primary care research by developing and supporting new researchers, research practices and research studies. The second but less explored area was developing local networks of primary care organizations, allowing new roles and collaborations to develop. Studies have consistently shown that primary care research networks contributed to building primary care networks per se, drawing in a wide range of primary care staff and building important links across practices. How far the new national framework with more centrally driven agendas can achieve the broad base of activity generated through the initial networks is yet to be seen, but, as suggested earlier, their focus is narrower both in terms of the type of research and who gets involved. Many of the perceived benefits of the locally developed UK PCRNs of the 1990s are not priority activities for these new centrally defined networks. These new networks are likely to more clearly differentiate those practices which are places for research from elite researchers who engage in the development and running of trials. While of value in developing primary care-relevant research, the new structures may fail to develop research-receptive practices and practitioners.

Drawing on the experiences of the United Kingdom and United States, there have been concerted efforts to develop PCRNs in Australia and New Zealand. The main advantages 
of these networks has been the way that they not only encouraged primary care-relevant research but also created local links and built research relationships. The networks were inclusive, involving a wide range of primary care practitioners - a key strength when considering the diversity of the primary care workforce. The networks were not elitist and provided seed money for developing projects, writing up research results and supporting practitioner training. They also provided a way of identifying local primary care research problems and supporting the development of project proposals (through funding, research methods support, etc.) to apply for research funding from established funding sources. These kinds of activities are not prioritized in the new national PCRNs, and it is possible that networks mandated centrally are more likely to prioritize national issues and focus on clinical trials. In the United Kingdom, the influence of previous locally driven experience in PCRNs has, however, been able to influence, to a certain extent, the nature of the new PCRNs and the development of a national school of primary care within the newly formed National Institute for Health Research. In fact, many of the leaders of the previous local PCRNs are in positions of local or national leadership within the clinical research networks and departments of academic primary care.

No comparison of large-scale national and locally driven networks has been undertaken. However, the UK experience suggests that national or larger centrally driven networks are more clinically focused and see primary care as a location for research rather than being developmental (Evans et al. 1997; Green and Dovey 2001; Thomas et al. 2001; Berg 2010). Key aspects of local and national primary care networks are summarized in Table 2.

TABLE 2. Assessing PCRN impacts

\begin{tabular}{|c|c|}
\hline Research/clinical outcomes & $\begin{array}{l}\text { Developing multidisciplinary research reflecting the structure of general practice } \\
\text { Engaging practitioners in research - as collaborators or as sites for research } \\
\text { Training in methods } \\
\text { Providing funding for practitioners to study, write and prepare proposals } \\
\text { Helping develop research awareness among primary care practitioners } \\
\text { Improving the quality of clinical practice }\end{array}$ \\
\hline Organizational outcomes & $\begin{array}{l}\text { Building local practice/practitioner networks } \\
\text { Creating research leaders } \\
\text { Embedding a research culture in primary care organizations } \\
\text { Promoting quality in primary care organizations } \\
\text { Providing career development opportunities for primary care staff }\end{array}$ \\
\hline
\end{tabular}

\section{Conclusions and Lessons for Canada}

The attraction of large-scale, centrally driven networks is that they can benefit from economies of scale and can be used to address national agendas. However, based on the UK experience, locally driven networks provide more adaptive "communities" of researchers that can address broader research goals and generate a primary care research community that can identify, develop, lead, participate and implement relevant research at the practice and local levels. Given the 
current state of Canadian primary care and the recognized need to develop the role of primary care in healthcare delivery, improve the quality and outcomes of primary care, develop more collaboration and mutual support among primary care providers and create opportunities for primary care leadership, further development of practice-based research networks seems warranted.

Given the different (and potentially complementary) strengths of bottom-up, self-forming local or regional practice-based networks and national "networks of excellence," and the lack of definitive evidence of superior impact of either model on ultimate health system performance, Canada should resist the impulse to choose between the two approaches and, instead, strive for a judicious balance between them. Practice-based networks support grassroots capacity-building and contextually relevant research evidence and foster communities of practice. This approach appeals to clinicians motivations to improve the care they deliver and the quality of their work life. National networks support large-scale research that engages senior researchers and addresses issues of national importance. Given the wide variation of primary care models both within and across provinces and territories, Canada offers a vast natural experiment that can be exploited through cross-jurisdictional research to yield policy-relevant insights regarding the organization, funding and delivery of primary care. Accordingly, integrating the two approaches seems likely to be the most effective means of establishing a flourishing and sustainable primary care research community in Canada that can inform policy and practice to the benefit of Canadians.

Building on existing and planned initiatives, this could happen in a number of ways. CIHR and provincial/territorial and regional research funders could support new and expanded practice-based research networks, drawing on the UK experience of impacts and the work of Bleeker and colleagues (2010) to set criteria for funding. The work of these networks could be coordinated and supported through future iterations of the Canadian Primary Care Sentinel Surveillance Network (CPCSSN), which could in turn be linked to, or ultimately incorporated into, the Patient-Oriented Community-Based Primary Healthcare Network funded by CIHR. One can imagine, for example, a set of regional hubs that incorporate practice-based networks, CBPHC Innovation Team members located in the region, CIHR-funded Health Professional Scientists, university-based CBPHC researchers and key regional CBPHC stakeholders woven together at the pan-Canadian level by the Patient-Oriented CBPHC Network.

Canada and the Canadian Institutes of Health Research are embarking on a new era of targeted investments in community-based primary healthcare research. Thoughtful reflection on the UK experience over the last 35 years may help make the most of those investments.

Correspondence may be directed to: Stephen Peckham, Centre for Health Services Studies, University of Kent, Canterbury, UK; tel.: +441227827645lemail: S.Peckham@kent.ac.uk.

\section{REFERENCES}

Berg, A.O. 2010. “What Do We Get from Participating in Practice-Based Research Networks?" Journal of the American Board of Family Medicine 23(4): 440-41.

Birtwhistle, R. 2011. “Canadian Primary Care Sentinel Surveillance Network: A Developing Resource for Family Medicine and Public Health." Canadian Family Physician 57: 1219-20. 
Bleeker, J.M.C., W.A.B. Stalman and H.E. van der Horst. 2010. “Evaluating Primary Care Research Networks: A Review of Currently Available Tools." Journal of the American Board of Family Medicine 23(4): 465-75.

Bradley, F., R. Wiles, A.-L. Kinmonth and M. Gantley. 1999."Development and Evaluation of Complex Interventions in Health Services Research: Case Study of the Southampton Heart Integrated Care Project (SHIP)." British Medical Journal 318: 711-15.

Burstin, H. and D. Lanier. 2001. “Update from Funders: Center for Primary Care Research and Agency for Health Care Research and Quality." Med Care 39:309-311. doi:10.1097/00005650-200104000-00001

Canadian Health Services Research Foundation (CHSRF). 1999. "Issues in Linkage and Exchange between Researchers and Decision-Makers." Retrieved September 10, 2012. <http://www.chsrf.ca/migrated/pdf/event_ reports/linkage_e.pdf>.

Canadian Institutes of Health Research (CIHR). 2011a. CIHR Roadmap Signature Initiative: Community-Based Primary Healthcare. Ottawa: Author.

Canadian Institutes of Health Research (CIHR). 2011b. Canada's Strategy for Patient-Oriented Research. Ottawa: Author.

Canadian Institutes of Health Research (CIHR). 2012. Team Grant: Community-Based Primary Healthcare (The Transformative Community-Based Primary Healthcare Initiative). Ottawa: Author. Retrieved September 10, 2012. <http://www.researchnet-recherchenet.ca/rnr16/vwOpprtntyDtls.do?prog=1479\&view=currentOpps\&org=CI HR\&type $=\mathrm{AND} \&$ resultCount $=25 \&$ sort $=$ program\&all $=1 \&$ masterList $=$ true\# evaluation $>$.

Carter, Y.H., S. Shaw and B. Sibbald. 2000. “Primary Care Research Networks: An Evolving Model Meriting National Evaluation." British Journal of General Practice 50: 651-52.

De Maeseneer, J.M., M.L. van Driel, L.A. Green and C. van Weel. 2003. “The Need for Research in Primary Care." Lancet 362: 1314-19.

Department of Health. 2006a. Best Research for Best Health: A New National Health Research Strategy. London: Author.

Department of Health. 2006b. Sir David Cooksey's Review of UK Health Research. London: Author.

Dobrow, M., V. Goel and R. Upshur. 2004. “Evidence-Based Health Policy: Context and Utilisation.” Social Science and Medicine 58: 207-17.

Evans, D., M. Exworthy, S. Peckham, R. Robinson and P. Day. 1997. Primary Care Research Networks: Report to the South and West Research and Development Directorate. Southampton: Institute for Health Policy Studies, University of Southampton.

Fenton, E., J. Harvey and J. Sturt. 2007. “Evaluating Primary Care Research Networks.” Health Services Management Research 20: 162-73.

Gibbons, M., C. Limoges, N. Nowotny, S. Schwartzman, S. Scott and M. Trow. 1994. The New Production of Knowledge: Dynamics of Science and Research in Contemporary Societies. London: Sage.

Goodwin, N., E. Peck, T. Freeman and R. Posaner. 2004. Networks Briefing - Key Lessons for Networks. London, England: NHS Service Delivery and Organisation Programme.

Green, L.A. and S.M. Dovey. 2001. “Practice Based Primary Care Research Networks." British Medical Journal 322: 567-68.

Green, L.A. and J. Hickner. 2006. "A Short History of Primary Care Practice-Based Research Networks: From Concept to Essential Research Laboratories." Journal of the American Board of Family Medicine 19(1): 1-10.

Griffiths F., W. Wild, J. Harvey and E. Fenton. 2000. "The Productivity of Primary Care Research Networks." British Journal of General Practice 50:9135.

Grzybowski, S. and L. Wallace. 2006. "Primary Care Research in Canada and the United States." Annals of Family Medicine 4(5): 466-67.

Hanney, S., M. González Block, M. Buxton and M. Kogan. 2003. “The Utilisation of Health Research in PolicyMaking: Concepts, Examples and Methods of Assessment." Health Research Policy and Systems 1(2). Retrieved September 10, 2012. <http://www.health-policy-systems.com/content/pdf/1478-4505-1-2.pdf>.

Hay, E.M., S.M. Paterson, M. Lewis, G. Hosie and P. Croft. 1999."Pragmatic Randomised Controlled Trial of 
Local Corticosteroid Injection and Naproxen for Treatment of Lateral Epicondylitis of Elbow in Primary Care." British Medical Journal 319: 964-68.

Howe, A., H. Leishman and H. MacDonald. 2009. “Fit for Purpose - A Regional Case Study in Primary Care Research Partnerships." Primary Care Research and Development 10: 7-13.

Hutchison, B., J.-F. Lévesque, E. Strumpf and N. Coyle. 2011. “Primary Health Care in Canada: Systems in Motion." Milbank Quarterly 89(2): 256-88.

Jaakkimainen, L., R. Upshur, J. Klein-Geltink, A. Leong, S. Maaten, S. Schultz and L. Wang. 2006. “Primary Care in the Health System." In L. Jaakkimainen et al., Primary Care in Ontario (Chapter 1). Toronto: Institute for Clinical Evaluative Sciences.

Jolly, K., F. Bradley, S. Sharp, H. Smith, S. Thompson, A.L. Kinmonth et al. 1999.“"Randomised Controlled Trial of Follow-up Care in General Practice of Patients with Myocardial Infarction and Angina: Final Results of the Southampton Heart Integrated Care Project (SHIP)." British Medical Journal 318: 706-11.

Lattimer, V., S. George, F. Thompson, E. Thomas, M. Mullee, J. Turnbull, et al. 1998. “Safety and Effectiveness of Nurse Telephone Consultation in Out-of-Hours Primary Care: Randomised Controlled Trial." British Medical Journal 317: 1054-59.

Lomas, J., N. Fulop, D. Gagnon and P. Allen. 2003، “On Being a Good Listener: Setting Priorities for Applied Health Services Research." Milbank Quarterly 81(3): 363-88.

Mold J.W. and K.A. Peterson. 2005."Primary Care Practice-based Research Networks: Working at the Interface between Research and Quality Improvement." Annals of Family Medicine 3(Suppl 1):S12-20.

Nutley, S. and H. Davies. 2000. "Making a Reality of Evidence-Based Practice: Some Lessons from the Diffusion of Innovations." Public Money \& Management 20(4): 35-42.

O'Neill, P. and P. Kelly. 1996. "Postal Questionnaire Study of Disability in the Community Associated with Psoriasis." British Medical Journal 313: 919-21.

Rait, G., S. Rogers and P. Wallace. 2002.“Primary Care Research Networks: Perspectives, Research Interests and Training Needs of Members." Primary Care Research and Development 3: 4-10.

Russell, G., R. Geneau, S. Johnston, C. Liddy, W. Hogg and K. Hogan. 2007. Mapping the Future of Primary Healthcare Research in Canada. Ottawa: Canadian Health Services Research Foundation. Retrieved September 10, 2012. <http://www.chsrf.ca/migrated/pdf/researchReports/commissionedResearch/mapping_future_ report_2007_e.pdf $>$.

Schoen, C., R. Osborn, M.M. Doty, D. Squires, J. Peugh and S. Applebaum. 2009. "A Survey of Primary Care Physicians in Eleven Countries 2009: Perspectives on Care, Costs, and Experiences." Health Affairs Web Exclusive 28(6): w1171-w1183.

Schoen, C., R. Osborn, D. Squires, M. Doty, R. Pierson and S. Applebaum. 2010. “How Health Insurance Design Affects Access to Care and Costs, by Income, in Eleven Countries." Health Affairs 29(12): 1-12.

Schoen, C., R. Osborn, D. Squires, M. Doty, R. Pierson and M. Applebaum. 2012."New 2011 Survey of Patients with Complex Care Needs in Eleven Countries Finds That Care Is Often Poorly Coordinated." Health Affairs 30(12): 2437-48.

Scullard, P., A. Abelhamid, N. Steel and N. Qureshi. 2011. "Does the Evidence Referenced in NICE Guidelines Reflect a Primary Care Population?" British Journal of General Practice 61(584): e112-e117.

Secretary of State for Health. 1996. Primary Care: Delivering the Future. London: Her Majesty's Stationery Office. Starfield, S. 2008. "Primary Care in Canada: Coming or Going?” Healthcare Papers 8(2): 58-62.

Stryer, D., S. Tunis, H. Hubbard and C. Clancy. 2000.“The Outcomes of Outcomes and Effectiveness Research: Impacts and Lessons from the First Decade." Health Services Research 35: 977-93.

Sweeney, K.G., D. MacAuley and D.P. Gray. 1998. “Personal Significance: The Third Dimension.” Lancet 351: 134-36.

Thomas P. 1985. The Aims and Outcomes of Social Policy Research. London, Croom Helm.

Thomas, P., J. Graffey, P. Wallace and M. Kirby. 2006. “How Primary Care Networks Can Help Integrate Academic and Service Initiatives in Primary Care." Annals of Family Medicine 4(3): 235-39. 
Thomas, P., F. Griffiths, J. Kai and A. O’Dwyer. 2001. “Networks for Research in Primary Health Care.” British Medical Journal 322: 588-90.

Thomas, P. and While A. 2001."West London Research Network. Increasing Research Capacity and Changing the Culture of Primary Care towards Reflexive Inquiring Practice." Journal of Interprofessional Care 15: 133-39.

Weiss, C. 1979. “The Many Meanings of Research Utilization." Public Administration Review 39(5): 426-31. 